\title{
Jogos Educativos e os Temas Transversais: $O$ Desenvolvimento de um Jogo para Discutir Política na Escola
}

\author{
Jéssica A. Silva ${ }^{1}$, Janio Carlos Nascimento Filho', Luciano Correia \\ Franco $^{1}$ \\ ${ }^{1}$ Licenciatura em Computação - Instituto Federal de Educação, Ciência e \\ Tecnologia do Tocantins (IFTO) - Porto Nacional, TO - Brazil \\ jessicaairesma@yahoo.com.br, janio.carloseifto.edu.br, \\ lucianofrancodifto.edu.br
}

\begin{abstract}
Brazil is one between 31 countries in the world to maintain compulsory voting. To increase the effectiveness and reduce abstention rates is interesting the country invest in education policy. This article presents a computer game that aims to increase political knowledge of future voters. This game has the potential to be used with children and teenagers, especially aged 16 and 17 where voting is optional, as a resource to increase the political awareness in school, as well as information for building a citizen aware of the importance of voting. In the proposed game, the player through a quiz related to the job function, where they are presented three options for each job function in questions.
\end{abstract}

Resumo. O Brasil é um dos 31 países do mundo a manter o voto obrigatório. Para ampliar a eficácia e reduzir os índices de abstenção é interessante ao país investir na educação política. Este artigo apresenta um jogo de computador que visa aumentar o conhecimento politico dos futuros eleitores. Este jogo tem potencial para ser utilizado com crianças e jovens, principalmente com 16 e 17 anos em que o voto é facultativo, como um recurso para ampliar a consciência politica na escola, bem como informação para construção de um cidadão ciente da importância do voto. No jogo proposto, o jogador através de um quiz relaciona a função a cargo, onde são apresentada três opções de cargo para cada função nas questões.

\section{Introdução}

No Brasil, o voto compulsório é previsto na Constituição Federal a partir dos 18 anos, o sufrágio é facultativo para analfabetos, idosos com mais de 70 anos de idade e jovens com 16 e 17 anos. Dessa forma, o sistema eleitoral brasileiro navega na contramão das democracias ao redor do planeta. $\mathrm{Na}$ grande maioria dos países, o voto é voluntário. Em reportagem publicada recentemente, "o sociólogo Eurico Cursino, da UnB, avalia que o dever de participar das eleições é uma pratica pedagógica. Ele argumenta que essa é uma forma de canalizar conflitos graves ligados às desigualdades no país", (GOMES, 2014).

$\mathrm{O}$ acesso à educação política ainda é muito tímido em nossa sociedade apesar da sua necessidade, considerando a obrigatoriedade do voto. Para disseminar conteúdos 
de atualização, formar e especializar magistrados da Justiça Eleitoral e população em geral incluindo os jovens foi criada a Escola Judiciária Eleitoral.

A Escola Judiciária Eleitoral (EJE) é um iniciativa do TSE (Tribunal Superior Eleitoral). O objetivo principal era formar, atualizar e especializar magistrados da Justiça Eleitoral, membros do Ministério Público e interessados em Direito Eleitoral. A partir da criação da EJE no TSE foram criadas escolas judiciárias em todos os Tribunais Regionais Eleitorais (BRASIL, 2015), posteriormente a EJE deu espaço para novas iniciativas como cartilhas para eleitores e a EJE Adolescente. A Escola Judiciária Eleitoral para adolescentes apresenta o conteúdo em linguagem simples e acessível com o intuito de despertar nesse público o interesse pela política e pela escolha consciente dos representantes, observadas as regras eleitorais, para isso a pagina conta com o jogo do eleitor eletrônico, curiosidades, palavras-cruzadas e caça-palavras. Todo material é encontrado no próprio site do TSE com acesso livre.

Mesmo com a EJE a educação politica não pode ser considerada de alcance a todos os jovens, os mesmos precisam acessar aos conteúdos por conta própria. A escola seria uma alternativa para garantir o contato dos jovens com o tema e despertar neles a vontade de aprimorar seus conhecimentos. Segundo o TSE no ano de 2014 a abstenção do eleitorado valido chegou a $21,50 \%$ no segundo turno das eleições.

Diante desse panorama, há uma necessidade de promover a educação política, preparando melhor os futuros eleitores brasileiros, com o objetivo, em longo prazo, de aumentar a consciência sobre a importância do voto e a participação política.

\section{Referencial Teórico}

A educação política é um tema transversal que apresenta diversos desafios e acredita-se que ela possa se beneficiar dos jogos educacionais digitais como recurso de ensino e aprendizagem.

Os temas transversais, segundo o Ministério da Educação, "são temas que estão voltados para a compreensão e para a construção da realidade social e dos direitos e responsabilidades relacionados com a vida pessoal e coletiva". Eles devem ser abordados dentro das disciplinas ou fora do ambiente escolar (SEF/MEC, 1998).

É preciso entender que, "na escola, o computador deve ser usado não como um substituto do professor, mas como um recurso auxiliar de que ele dispõe para facilitar o desenvolvimento do trabalho pedagógico interdisciplinar" (HAIDT, 2003, p. 280).

O jogo é uma maneira de imitar situações reais ou fictícias, permitindo ao homem fazer descobertas, desenvolver sua criatividade, ir ao encontro do eu e do outro e renovar sua energia. Por meio do jogo se aprende a agir, estimulando a curiosidade, a iniciativa e autoconfiança, ao mesmo tempo em que o desenvolvimento da linguagem, do pensamento e da concentração é proporcionado. Os jogos podem, portanto, desenvolver as capacidades intelectuais do jogador (SANTOS 2006).

Como observado os jogos se apresentam como uma boa ferramenta para se trabalhar a educação política nas escolas. 


\section{Metodologias e Ferramentas Utilizadas}

A proposta de criação de jogo educativo foi realizada na disciplina de Computação Gráfica no sexto período do curso de Licenciatura em Computação do IFTO Campus Porto Nacional. Inicialmente, foram realizadas pesquisas de demanda de temas a serem trabalhados nas escolas e que pudessem ser aplicados a jogos educativos segundo o interesse de cada aluno. A proposta de jogo para educação política foi inspirada após uma profusão de pesquisas sobre o desconhecimento do eleitorado acerca das funções da classe política. No site de notícias Gazeta do povo, por exemplo, publicou $42 \%$ dos eleitores de Curitiba não sabem o que faz um vereador. $O$ levantamento de opinião realizado pelo Instituto Paraná Pesquisas ocorreu no ano de 2012, ano de eleições.

Com a escolha do tema a ser trabalhado, foram realizadas pesquisas no site do TSE e revistas de educação para a caracterização do problema e levantamento dos principais requisitos do jogo. Em seguida, foram selecionados livros e artigos de computação gráfica e jogos computacionais para estudo de forma a prover uma fundamentação teórica quanto à viabilidade técnica para o desenvolvimento do jogo para educação política.

A aplicação foi desenvolvida na plataforma de Sistema Operacional Linux Mint 17 "Rebecca", isso possibilitou perfeita portabilidade do executável final nos ambientes Ubuntu 14.04 LTS e Linux Educacional 5.0 (Distribuição Linux amplamente utilizada nas escolas públicas). Para a confecção do jogo, foi utilizada a biblioteca gráfica OpenGL e o kit de utilidades GLUT. O arquivo fonte foi escrito em $\mathrm{C}$. Utilizamos também a ferramenta IDE CodeBlocks. Estruturamos os dados em arquivos e possibilitamos através de tutorial que os futuros usuários (preferencialmente, professores) pudessem personalizar a aplicação.

\section{Resultados}

O cenário do jogo simula a caminhada do jogador ao seu local de votação. Com a representação de uma trilha feita por "casas" quadriculadas o jogador precisa responder algumas questões para avançar sua caminhada e chegar ao seu local de votação. As questões no jogo abordam as funções de representantes políticos das três esferas divididas em: legislativo, executivo e judiciário.

Quando um jogador consegue responder corretamente uma questão, ele avança uma "casa" e segue no jogo sem intervenções, quando o jogador erra a resposta da questão apresentada ele a resposta correta ao cargo que se atribui no sistema político do Brasil aquelas funções o fazendo refletir sobre quem está atualmente ocupando aquele cargo no Brasil, no Tocantins ou em Porto Nacional.

Conforme cada acerto o jogador soma um ponto no campo de acerto, com o erro o jogador segue para próxima questão após ver a resposta correta e segue somando um ponto no campo de erro. Isso serve para o próprio jogador observar quantitativamente ao final do jogo como foi seu desempenho até seu local de votação.

O resultado do primeiro protótipo pode ser observado na figura abaixo. 
A

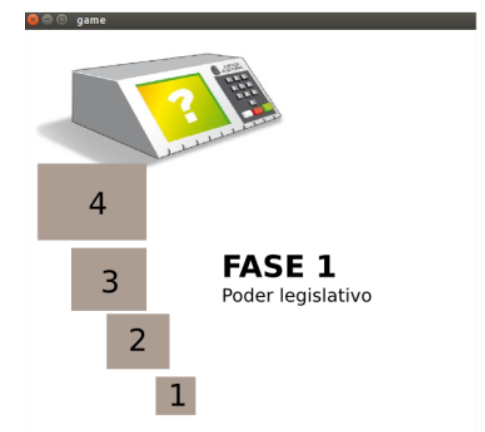

B

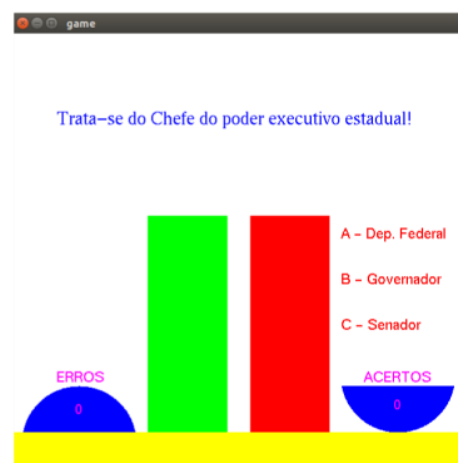

Figura 1 - (A) Exemplo de tela de fase. (B) Exemplo de questão.

Espera-se ao final das questões que o jogador chegue ao seu local de votação e seja apresentada a importância do voto no Brasil e a implicação da sua decisão no sistema político. Em momento oportuno, será realizado o teste de aceitação do jogo com alunos do ensino fundamental e médio de escolas públicas no município de Porto Nacional - TO para que se possa receber um feedback de professores e estudantes.

\section{Conclusão}

Com as dificuldades enfrentadas para o desenvolvimento desse jogo, foi possível compreender a dificuldade de se trabalhar com temas transversais na escola. A grade curricular do curso de Licenciatura em Computação promove diversos conhecimentos ao acadêmico, porem alguns conteúdos específicos tornam-se mais difíceis de serem trabalhados principalmente pela falta de contato no dia-a-dia do estudante, nesse caso a política.

A educação política ainda é muito tímida em nossa sociedade. Nas escolas assunto é abordado nas disciplinas de história, geografia, sociologia e filosofia, mas exclusivamente para embasar contextos. A importância e valor que cada voto tem não é rotineiramente discutido em sala de aula é assim muitos acabam votando por obrigação e não por ato de cidadania. Desta forma, possibilitar, por meio de jogos digitais educacionais, que o jovem aprenda um pouco mais sobre a função de cada político, pode ser uma estratégia significativa de apresentar ao eleitor a importância de pesquisar o melhor candidato para a função e cobrar sua atuação após eleito.

Neste trabalho foi apresentado um jogo para educação política visando ampliar o conhecimento dos jovens sobre política para aproximá-los de forma recreativa do tema com questões objetivas para testar seus conhecimentos e aproxima-los de uma conscientização da importância do voto.

Pretende-se em trabalhos futuros, analisar (1) a aceitação do jogo por alunos e professores; (2) sua aplicabilidade no ensino de cidadania, bem como (3) levantar formas de tornar mais lúdico e atraente o aprendizado através do jogo.

\section{Referências}

HAIDT, Regina Célia. Curso de didática geral. São Paulo: Ática, 2003. 
Gomes, Karina. O voto deveria ser facultativo no Brasil?. Carta Capital, São Paulo, 25 ago. 2014. Disponível em: < http://www.cartacapital.com.br/politica/o-voto-deveria ser-facultativo-no-brasil-1293.html >. Acesso em: 27 mai. 2015.

SEF/MEC. Secretaria de Educação Fundamental. Parâmetros curriculares nacionais: terceiro e quarto ciclos: apresentação dos temas transversais. Brasília, 1998.

BRASIL, Tribunal Superior eleitoral - TSE. Escola Judiciária Eleitoral. Disponível em: $<$ http://www.tse.jus.br/institucional/escola-judiciaria-eleitoral/institucional $>$. Acesso em: 30 mai. 2015.

SANTOS,C.L.Jogos Eletrônicos na Educação: Um Estudo da Proposta dos jogosEstratégicos. São Cristovão.2006. Disponível em: $<$ http://www.institutodosjogos.com/wpcontent/downloads/jogos_eletronicos_na_edu cacao.pdf. $>$ Acesso em 28 set. 2014.

MOSER,Sandro. 42\% dos eleitores de Curitiba não sabem o que faz um vereador. Gazeta do Povo, Curitiba, 03 abr. 2012. Vida Publica. Disponível em: $<$ http://www.gazetadopovo.com.br/vida-publica/42-dos-eleitores-de-curitiba-naosabem-o-que-faz-um-vereador-1t5x17haswk0r27yr69rt3az2> Acesso em 19 jul. 2015. 